\title{
Policy Proposal Related to Solar Power Generation System Using Real Option Analysis
}

\author{
Yoshihiko Yamada and Ryuji Matsuhashi
}

\begin{abstract}
A FIT system obligating a power transmission and distribution company to procure renewable energy in fixed time and price began due to a Fukushima Daiichi nuclear disaster. However, a national burden becomes heavy and a renewable energy introduction is delayed owing to some reasons. In this paper, we aim to be compatible with easing the national burden and stimulating an investment. Furthermore, we evaluate an optimal certification period and a new system to replace the FIT using a real option analysis.
\end{abstract}

Index Terms-FIT, renewable energy, real option analysis, energy policy.

\section{INTRODUCTION}

Due to the Fukushima Daiichi nuclear disaster occurred in 2011, a thermal power plant operation rate is increased and it makes various problems such as rising of electric charges and $\mathrm{CO} 2$ emissions. Also, in recent years, the solar power generation system has attracted attention as its initial cost has sharply decreased [1]. Therefore, the feed-in tariff (FIT) system began in 2012 to familiarize a solar power generation system. The FIT obligate the power transmission and distribution company to procure renewable energy in fixed time and price. Purchase costs are subjected to people in the form of the renewable energy levy [2]. Fig. 1 shows the outline of the FIT.

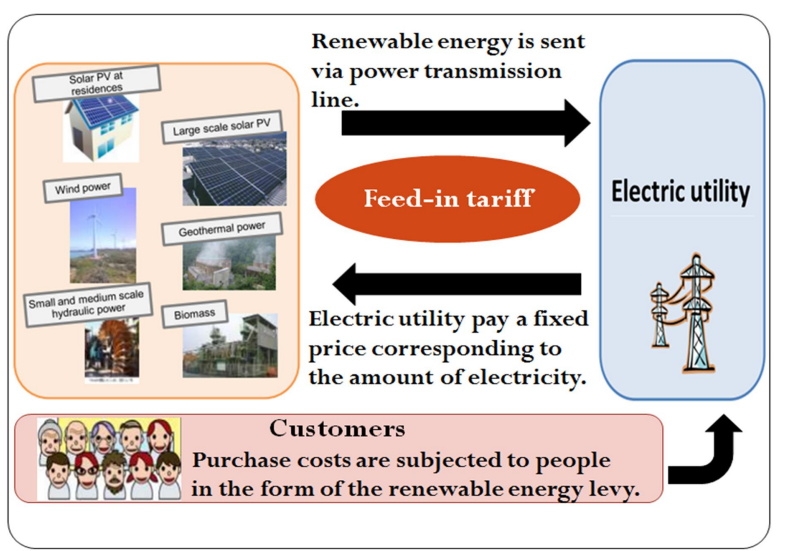

Fig. 1. Outline of the FIT [3].

However, renewable energy levy on citizens have increased in countries that introduced the FIT ahead of Japan, and it continue to increase even in Japan. According to the report of the Agency for Natural Resources and Energy, the annual renewable energy levy per household is

Manuscript received October 17, 2016; revised May 18, 2017.

The authors are with Dept. of Electrical Engineering and Information System, the University of Tokyo, Japan (e-mail: yamada@enesys.t.u-tokyo.ac.jp, matu@k.u-tokyo.ac.jp). rapidly growing at about 1000 yen in 2012, about 1400 yen in 2013, and about 2700 yen in 2014. In addition, the introduction of the solar power generation system is not progressed since many power producers have waited until initial cost decreases. To solve such problems, the revised FIT was enacted in 2016 and a bidding system was expected to apply in mega-solar. However, the bidding system might not stimulate investment since there is a risk which can't be successful bid.

In this paper, we focus on $10 \mathrm{MW}$ mega-solar power generation business in Tokyo. We assumed some scenarios of the certification period in order to evaluate how much it can stimulate the investment. In addition, we assumed an original system in order to evaluate how much decrease the renewable energy levy. In order to evaluate these assumptions, we used real option analysis.

\section{METHODS}

\section{A. Real Option Analysis}

We use the investment evaluation method called real option analysis. Real option analysis is a model that can evaluate in consideration of optimal investment judgment according to future uncertainty. Although there are various uncertainties in the business and businesses may cancel or postpone the investment, it is possible to evaluate the business performance in consideration of flexible decision making with real option analysis [4], [5].

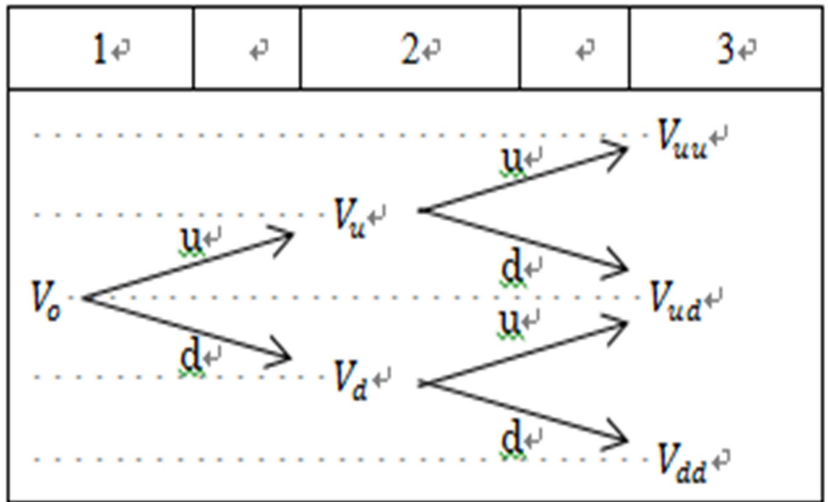

Fig. 2. Underlying asset lattice.

Next, we will explain how the investment evaluation will be carried out using examples in three periods. First, we need to determine an underlying asset lattice shown Fig. 2. The underlying asset $V_{0}$ becomes $V_{u}$ and $V_{d}$ multiplied by an increasing rate $\mathrm{u}$ and a decreasing rate $\mathrm{d}$ after 1 period. Similarly, $V_{u}$ and $V_{d}$ become $V_{u u}, V_{u d}$, and $V_{d d}$ multiplied by $\mathrm{u}$ and $\mathrm{d}$ after another period. The $\mathrm{u}$ and $\mathrm{d}$ can be expressed by the following Eq. 1 and 2 . 


$$
\begin{gathered}
\mathrm{u}=e^{\sigma \sqrt{d t}} \\
\mathrm{~d}=e^{-\sigma \sqrt{d t}}=\frac{1}{u}
\end{gathered}
$$

The $\mathrm{dt}$ means the length of one period and this time we adopted $\mathrm{dt}=1$. Also, $\sigma$ means the standard deviation.

Second, we need to determine an option valuation lattice shown Fig. 3. We need to calculate from the final period to the first period. The option valuation of the final period $C_{u u}$, $C_{u d}$, and $C_{d d}$ can be expressed by the following Eq.3, 4 and 5 .

$$
\begin{aligned}
& C_{u u}=\operatorname{Max}\left(V_{u u}, 0\right) \\
& C_{u d}=\operatorname{Max}\left(V_{u d}, 0\right) \\
& C_{d d}=\operatorname{Max}\left(V_{d d}, 0\right)
\end{aligned}
$$

The option valuation except for the final period $C_{u}, C_{d}$ and $C_{0}$ can be expressed by the following Eq.6, 7 and 8 using a risk-neutral probability $\mathrm{p}$ and a discount rate $\mathrm{r}$.

$$
\begin{gathered}
C_{u}=\operatorname{Max}\left(\frac{p \times C_{u u}+(1-p) \times C_{u d}}{1+r}, V_{u}\right) \\
C_{d}=\operatorname{Max}\left(\frac{p \times C_{u d}+(1-p) \times C_{d d}}{1+r}, V_{d}\right) \\
\operatorname{Co}=\operatorname{Max}\left(\frac{p \times C_{u}+(1-p) \times C_{d}}{1+r}, V_{0}\right)
\end{gathered}
$$

The risk-neutral probability means the probability of being artificial. For example, in the risk-less world, the risk premium corresponding to the risk is added to the revenue of the risky asset. Therefore, if you remove the risk, the revenue will decrease by the risk premium. If we remove the risk, the revenue will decrease by the risk premium. The $p$ can be expressed by the following Eq. 9 .

$$
\mathrm{p}=\frac{e^{\mu}-d}{u-d}
$$

The $\mu$ means the average of change rate.

It will be the investment if $\mathrm{V}$ is greater than 0 in the final period. On the other hand, it will be the investment if $\mathrm{V}$ is greater than $\mathrm{C}$ except for final period. In this way, we calculate the investment rate in all uncertainty patterns.

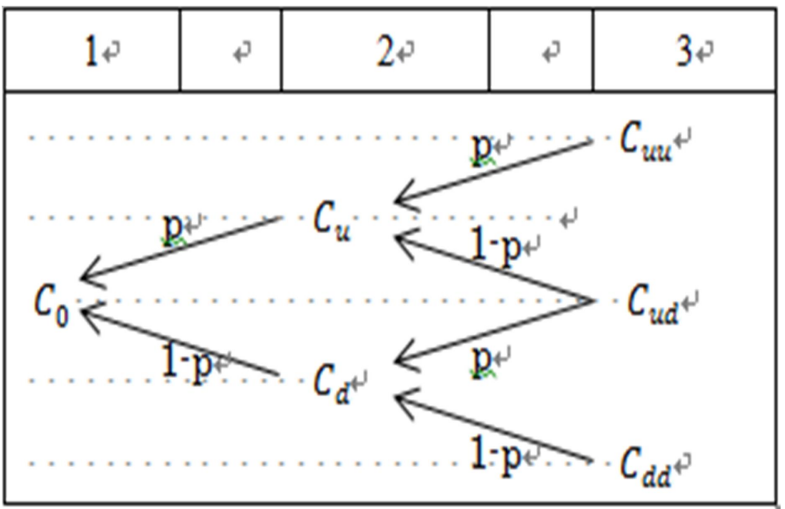

Fig. 3. Option valuation lattice.

\section{B. Underlying Asset Model}

The underlying asset model can be expressed by the following Eq. 10, 11, 12, and $13\{0 \leq n, i, j, k \leq 20\}$.

$$
\begin{gathered}
V[\mathrm{n}][\mathrm{i}][\mathrm{j}][\mathrm{k}]=\frac{\sum_{t=1}^{20} 10^{4} \times I[n][i] \times K[n][k]}{(1+r)^{t}} \\
-J[n][j] \\
I[n][i]=25.38 \times u_{i}^{n-i} \times d_{i}^{i} \\
J[n][j]=1.52 \times 10^{9} \times u_{j}^{n-j} \times d_{j}{ }^{j} \\
K[n][k]=1.01 \times 10^{3} \times u_{k}^{n-k} \times d_{k}{ }^{k}
\end{gathered}
$$

I: tariff [yen $/ \mathrm{kWh}]$

$\mathrm{J}$ : initial cost [yen/10MW]

$\mathrm{K}$ : annual power generation $[\mathrm{kWh} / \mathrm{kW}]$

Also, the parameters of this model are shown in Table I.

TABLE I: PARAMETERS OF UNDERLYING ASSET MODEL

\begin{tabular}{|c|c|c|c|}
\hline & $\mathrm{I}$ & $\mathrm{J}$ & $\mathrm{K}$ \\
\hline $\mathrm{u}$ & 1.268 & 1.181 & 1.092 \\
\hline $\mathrm{d}$ & 0.789 & 0.847 & 0.915 \\
\hline$\sigma$ & 0.237 & 0.166 & 0.089 \\
\hline$\mu$ & -0.046 & -0.071 & 0.004 \\
\hline $\mathrm{pu}$ & 0.347 & 0.253 & 0.501 \\
\hline $\mathrm{pd}$ & 0.653 & 0.747 & 0.499 \\
\hline
\end{tabular}

In this model, we consider the tariff, the initial cost, and the annual power generation as the uncertainly. The tariff means purchase costs of renewable energy which is obligated to power transmission and distribution company [6], [7]. Initial cost means costs which include capital costs and $\mathrm{O} \& \mathrm{M}$ costs [8], [9]. The annual power generation means the annual energy production per installed capacity [10].

\section{Option Valuation Model}

The option valuation model can be expressed by the following Eq. 14 and $15\{0 \leq n, i, j, k \leq 20\}$.

$$
\begin{aligned}
& {[1] \mathrm{n}=20} \\
& \quad C[n][i][j][k]=\operatorname{Max}(S[20][i][j][k], 0)
\end{aligned}
$$

[2] $0 \leq \mathrm{n} \leq 19$

$$
\begin{gathered}
C[n][i][j][k]=\operatorname{Max}( \\
p_{i} \times p_{j} \times p_{k} \times C[n+1][i][j][k]+ \\
p_{i} \times p_{j} \times\left(1-p_{k}\right) \times C[n+1][i][j][k+1]+ \\
p_{i} \times\left(1-p_{j}\right) \times p_{k} \times C[n+1][i][j+1][k]+ \\
\left(1-p_{i}\right) \times p_{j} \times p_{k} \times C[n+1][i+1][j][k]+ \\
p_{i} \times\left(1-p_{j}\right) \times\left(1-p_{k}\right) \times C[n+1][i][j+1][k+1]+ \\
\left(1-p_{i}\right) \times\left(1-p_{j}\right) \times p_{k} \times C[n+1][i+1][j+1][k]+ \\
\left(1-p_{i}\right) \times p_{j} \times\left(1-p_{k}\right) \times C[n+1][i+1][j][k+1]+ \\
\left.\frac{\left.\left(1-p_{i}\right) \times\left(1-p_{j}\right) \times\left(1-p_{k}\right) \times C[n+1][i+1][j+1][k+1]\right)}{1+r}, 0\right) \\
S[n][\mathrm{i}][\mathrm{j}][\mathrm{k}]
\end{gathered}
$$

$p_{i}$ : Risk-neutral probability of tariff

$p_{j}$ : Risk-neutral probability of initial cost

$p_{k}$ : Risk-neutral probability of the annual power generation 


\section{Original System Model}

The original policy was in reference to the feed-in premium (FIP). The FIP is a method of adding a certain premium to the power market price which has been adopted in Europe [11], [12]. In this model, we adopted 5 years average of the power market price plus about $1.5 \mathrm{yen} / \mathrm{kWh}$ as the premium in consideration of $\mathrm{CO} 2$ reduction costs and purchased by power transmission and distribution operators for 20 years [13]. This original FIP will be compatible with stimulating the investment by reducing the risk of the power producer, and easing the burden on the public by reducing the tariff to a minimum. Original tariff model can be expressed by the following Eq. 16 .

$$
I[n][i]=14.1 \times u_{i}^{n-i} \times d_{i}^{i}+1.54
$$

Also, the parameters of this model are shown in Table II.

TABLE II: PARAMETERS OF ORIGINAL SYSTEM MODEL

\begin{tabular}{|c|c|}
\hline & $\mathrm{I}$ \\
\hline $\mathrm{u}$ & 1.292 \\
\hline $\mathrm{d}$ & 0.774 \\
\hline$\sigma$ & 0.256 \\
\hline$\mu$ & -0.031 \\
\hline $\mathrm{pu}$ & 0.378 \\
\hline $\mathrm{pd}$ & 0.623 \\
\hline
\end{tabular}

In this model, the minimum profit can be obtained by setting a premium, though business operator doesn't gain great profit. Therefore, it is considered that the investment rate will rise since the business operator should execute the business if it makes a little profit for the business operator.

\section{E. Cost Performance Model}

The cost performance model can be expressed by the following Eq. 17.

\section{Cost Performance}

$=\frac{\begin{array}{c}\text { Investment } \\ \text { rate }[\%]\end{array}}{\text { Renewable energy levy }\left[\frac{\text { yen }}{k W h}\right]}$

Also, renewable energy levy can be expressed by the following Eq. 18.

Renewable energy levy

(Purcahase cost of renewable energy [yen]) -

$$
=\frac{\text { Avoidable cost }[\text { yen }]}{\text { Sells amount of electric power }[\mathrm{kWh}]}
$$

In this model, we evaluate how much the investment rate increases when the renewable energy levy increases by 1 yen. In other words, the higher the cost performance, the more we can achieve our goal of increasing investment rates and decreasing renewable energy levy.

\section{RESULTS}

Fig. 4-Fig. 7 show the investment rate of FIT with respective restriction period. In case of 1 year restriction, the investment rate was overall high and had gradually decreased. In case of no restriction, the investment rate was overall low and had gradually increased. In case of 2 and 3 years restriction, the investment rate had rapidly increased in every two to three years and had gradually decreased. In case of all restriction period, the investment rate was increasing in the final period. Fig. 8 shows the cost performance compared with the FIT and the original FIP. Cost performance of the original FIP was better than that of the FIT, though the deference between the FIT and the original FIP had gradually narrowed. Besides, the cost performance of original FIP had gradually increased from the middle though it had gradually decreased at the beginning.
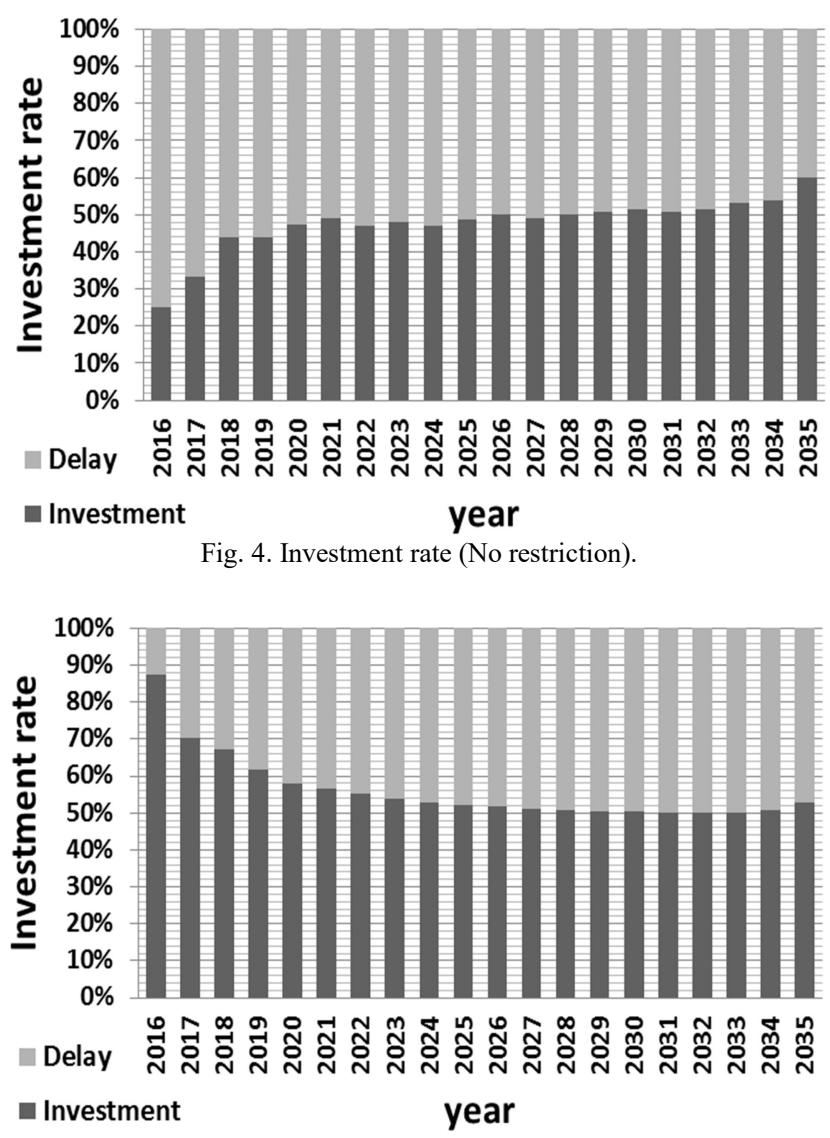

Fig. 5. Investment rate (1 year restriction).

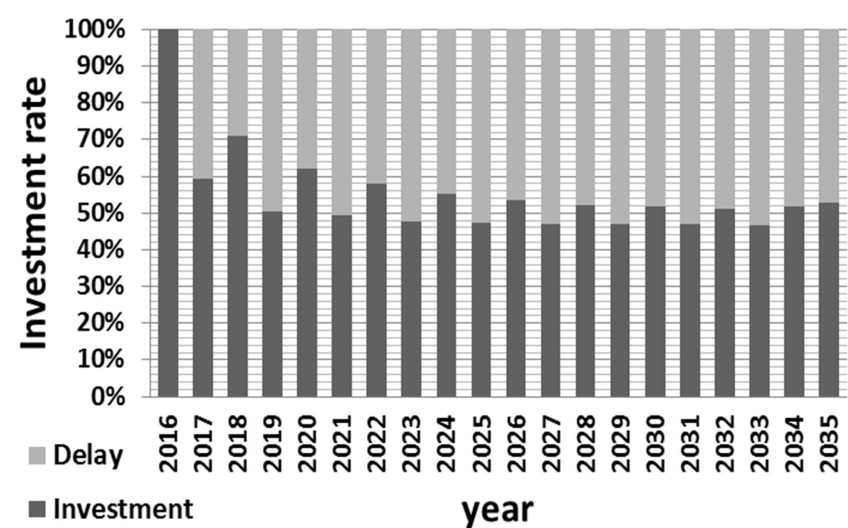

Fig. 6. Investment rate (2 years restriction).

\section{DISCUSSION}

We find the more the restriction period shortens, the more investment rate increases. Therefore, the restriction period is desirable to be as short as possible. The restriction period is 
considered 1 year as best since it takes about half a year to secure the land and the contractor of mega-solar and also it takes half a year to construct as of now. Also, we found that the investment rate was increasing in the final period. If business operators miss the final period, it will be impossible to execute the project. Therefore, it is assumed that last-minute demand has increased. In addition, we find that the FIP tariff has been set more properly than the FIT tariff. However, cost performance of the FIP decreased gradually. We need to calculate the premium which makes cost performance best in the range of about 1 2 yen since we adopted 1.5 yen premium which is $\mathrm{CO} 2$ reduction costs as of 2015 .

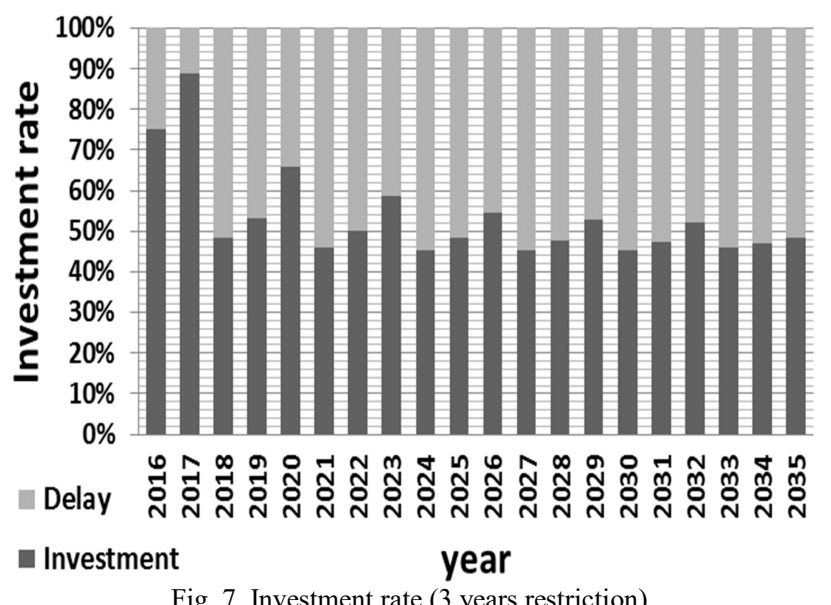

Fig. 7. Investment rate (3 years restriction).

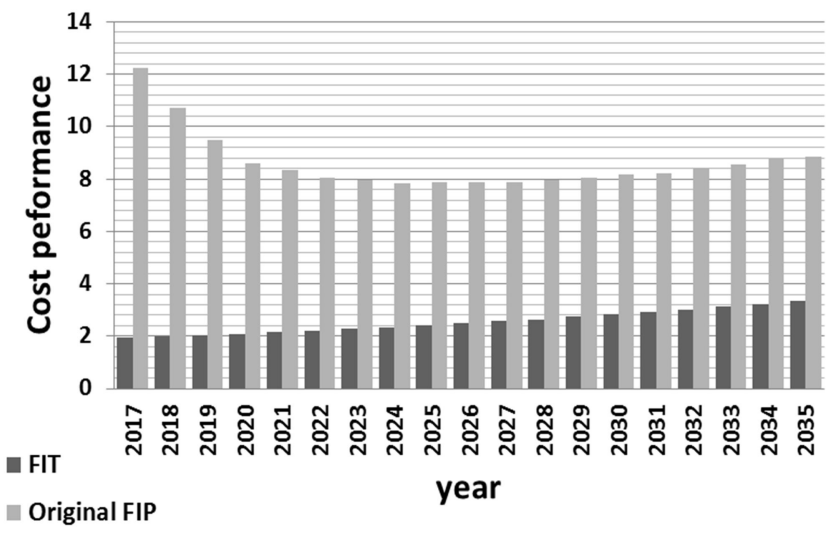

Fig. 8. Cost performance (FIT and original FIP).

In addition, we currently assume mega-solar power generation business in Tokyo, but in fact the output suppression has occurred in Kyushu, Hokkaido, and other regions [14], [15]. The output suppression means that power transmission and distribution company stop purchasing renewable energy since the output fluctuation cannot be fully absorbed. As output suppression is a major uncertainty for business operators, it is considered that the investment rate will decrease sharply in these regions. Therefore, in the future, it is necessary to create a model that takes this output suppression into account.

\section{CONCLUSIONS}

In this paper, we focus on $10 \mathrm{MW}$ mega-solar power generation business in Tokyo. We assumed some scenarios of the certification period in order to evaluate how much it can stimulate the investment. Also, we assumed an original system in order to evaluate how much decrease the renewable energy levy. In addition, we introduce the original FIP system to achieve both increasing in the investment rate and decreasing in renewable energy levy.

As a result, we found that 1 year restriction is best to stimulate the investment and the original FIP is better than the FIT in terms of cost performance. However, we need to reconsider the premium amount since cost performance has gradually decreased. Also, we need to consider the output suppression in other regions in order to make more accurate simulations.

\section{REFERENCES}

[1] D. Hochschild, "Growth of renewable energy in California IRED 2014," California Energy Commission, 2014.

[2] "Feed-in Tariff Scheme in Japan," Ministry of Economy, Trade and Industry, Agency for Natural Resources and Energy, 2012.

[3] "Feed-in Tariff Scheme for Renewable Energy," Ministry of Economy, Trade and Industry, Agency for Natural Resources and Energy, 2012.

[4] L. M. da S. Fenolio and A. M. A. F. Minardi, "Applying real options theory to the valuation of small hydropower plants," Revista de Economia e Administracao, vol. 8, no. 3, pp. 347-369, 2009.

[5] M. Kohama, T. Adachi, and C. Tokoro, "Real option analysis for deep-sea mineral resources development in Japanese waters," Journal of Real Options and Strategy, vol. 4, no. 1, pp. 101-116, 2011.

[6] "Spot Market Trading Results," Japan Electric Power Exchange, 2011-2015.

[7] “JEPA PV OUTLOOK 2030," Japan Photovoltaic Energy Association, 2013.

[8] "WEIO 2014-Power Generation Investment Assumptions," International Energy Agency, 2014.

[9] "PV Power Systems: Quantitative Technology Scenarios, and Science and Technology Roadmap based on Elemental Technology Structure," Strategy for Technology Development, Proposal Paper for Policy Making and Governmental Action toward Low Carbon Societies, 2014.

[10] "Table of Monthly Climate Statistics," Japan Meteorological Agency, 1975-2008.

[11] "Feed-in-Tariff vs Feed-in-premium Policies," Hellenic Association of Photovoltaic Companies, 2010.

[12] "A Policymaker's Guide to Feed-in tariff Policy Design," National Renewable Energy Laboratory, 2010.

[13] "CO2 emissions, $\mathrm{CO} 2$ emissions intensity and electricity sales," Tokyo Electric Power Company, 1992-2014.

[14] T. Makita, T. Kato, and Y. Suzuoki, "Experimental study of power output suppression control of photovoltaic power generation during electricity surplus in electric power system," Electrical Engineering in Japan, vol. 191, no. 1, 2015.

[15] "Evaluation of the PV Project with Consideration of Output Suppression," Strategy for Technology Development, Proposal Paper for Policy Making and Governmental Action toward Low Carbon Societies, 2016.

Ryuji Matsuhashi was born in 1963, Mr. Ryuji Matsuhashi earned the bachelor of engineering degree from the Department of Electronics, Faculty of Engineering, the University of Tokyo in 1985, and the doctor of engineering in 1990 from the same department.

He became an associate professor at the Department of Geosystem Engineering, Faculty of Engineering, University of Tokyo since 1994 after serving as the research associate of the same from 1990 to 1993 . Next, he has become an associate professor at the Institute of Environmental Studies, Graduate School of Frontier Sciences, the University of Tokyo, since 1999. Next, he has become a professor at the same institute of the University of Tokyo, since 2003. Then he has become a professor at the electrical engineering and information systems, Graduate School of Engineering in the same university, since 2011. 